\title{
Albanon
}

Revistë kulturore

\section{Selvitë e elbasanit sipas artistëve të huaj}

Ferid Hudhri

Deri nga fundi i viteve '70 të shekullit të kaluar, banorët e Elbasanit, si dhe udhëtarët që vinin nga krahina apo vende të tjera, vështronin thuajse çdo ditë, disa selvi të larta dhe shumë të lashta, në pjesën jugore të qendrës së qytetit, drejt rrugës për në Cërrik. Pemët kishin krijuar imazhin e një qendre çlodhëse. Shumë vite më parë, kur ishin më të gjelbëruara, rreth tyre grumbulloheshin, takoheshin dhe argëtoheshin njerëz të moshave të ndryshme. Aty kryheshin po ashtu edhe rite fetare. Më pas, ky mjedis i gjelbëruar, për disa kohë, u bë kamp sportiv, ndërsa vitet e fundit u vendos tregu i lirë për prodhimet nga fshati. Tani në atë vend nuk zhvillohet asnjë lloj veprimtarie dhe nuk ekziston më asnjë prej atyre selvive të larta. Imazhet e tyre kanë mbetur vetëm në kujtesën e banorëve më të moshuar si dhe në pak fotografi, thuajse të rastësishme. Ata drurë të lartë dikur quheshin Selvitë e Namazgjasë.

Ky monument i bukur natyror, një nga më të rrallët dhe më të veçantët në zonën e Elbasanit, është përmendur nga të huajt që para tre shekujsh. Turku Evlia Çelebi, gjatë udhëtimit të tij nëpër trojet shqiptare, në vitin 1662 e përshkruan këtë mjedis pemësh të larta në Sejjhatnamesi-n e tij (Përmbledhja "Udhëtimet", botuar në Stamboll në vitin 1902), si një bukuri e rrallë ku lëndina që bleron si kadife është e rrethuar me 57 selvi të mëdha e të bukura. Sipas këtij përshkrimi, kuptohet se Selvitë në vitin 1662 ishin në kulmin e lulëzimit të tyre (të mëdha dhe të bukura). Me siguri kanë qenë mbjellë shumë vite më parë se të kalonte turisti turk.

Pas një periudhe të gjatë, prej më se dy shekujsh, selvitë e Elbasanit paraqiten përsëri me madhështi për hijeshinë e tyre, nga një udhëtar tjetër i huaj. Përshkrimi është bërë sipas një lloji tjetër; me gjuhën e pikturës. Në vitin 1917, artisti vjenez Ludvig Hesshaimer (1872-1956), ka krijuar një 
nga tablotë më të bukura me këtë motiv. Selvitë e Elbasanit jepen nga një këndvështrim i atillë, ku majat e larta dhe të drejta, në pjesën e sipërme krijojnë një hapësirë në formë rrethore që bën të duket bukur qielli i ndriçuar nga yjet e një mbrëmjeje verore. Në pjesën e poshtme, pemët e vendosura pranë njëra-tjetrës ngjajnë si një mur i lartë, i padepërtueshëm. Nga këqyrja e vëmendshme e kësaj tabloje duket sikur selvitë ishin në kohën e plotë të lulëzimit të tyre, megjithëse kishin kaluar rreth tre shekuj nga përshkrimi i përafërt i udhëtarit turk E. Çelebi (?!).

Si drurë që kanë jetëgjatësi më të madhe se llojet e tjerë (sipas studimeve selvitë jetojnë deri në 2000 vjet, lartësohen deri $30 \mathrm{~m}$ ), duket një rast i rrallë që, edhe plot 255 vjet pas përshkrimit nga koha e lulëzimit të tyre (1662), ato të jenë përsëri po aq madhështore. Në periudhën kur $u$ pikturuan nga Hesshaimer ato kanë qenë ende impresionuese, aq sa $\mathrm{u}$ bënë objekt edhe i piktorëve të tjerë. Po atë vit janë pikturuar nga arkitekti Leopold Forstner (1878-1936), ndërsa pas 11 vjetësh, më 1927, Selvitë e Elbasanit u bënë objekt i anglezit Paul Edmonds. I befasuar nga madhështia dhe lashtësia e tyre ai krijoi tri grafika që paraqesin të njëjtin grupim pemësh

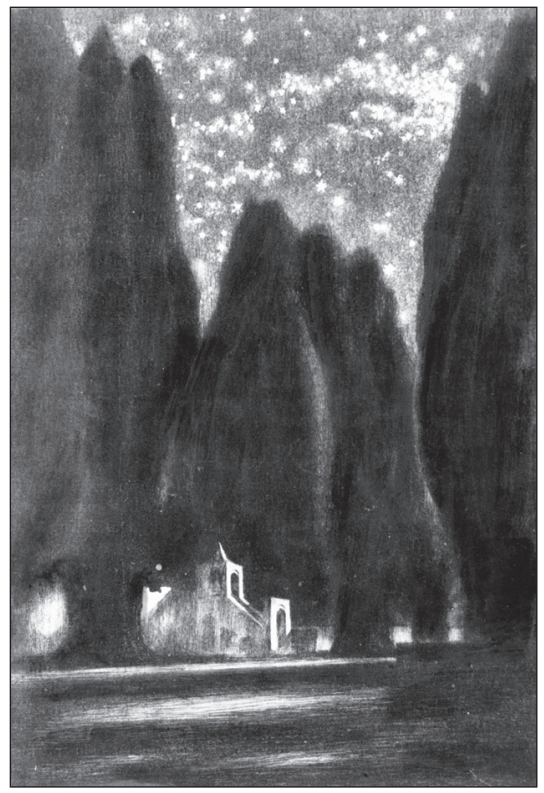

L. Hesshaimer, Selvitë në Elbasan, gravurë e vitit 1917

L. Forstner, Peizazh nga Elbasani, vizatim i vitit 1918

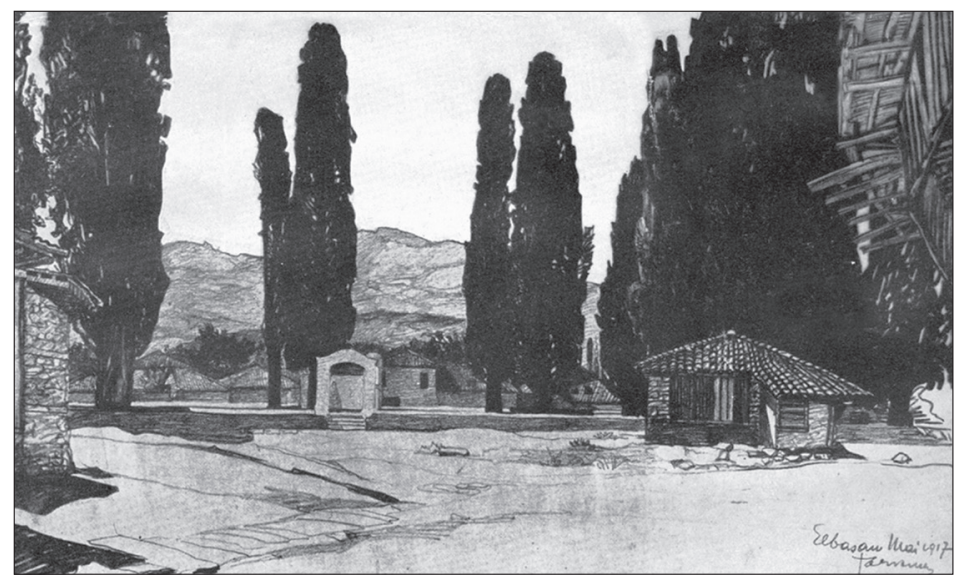




\section{Albanon}

Revistë kulturore
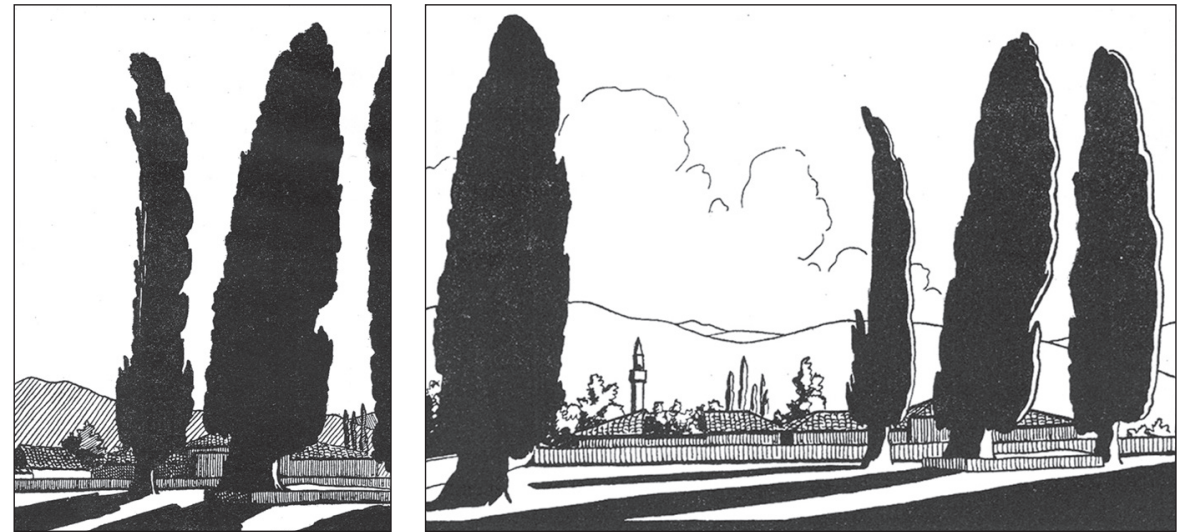

P. Edmonds, Selvitë në Elbasan, vizatime të vitit 1927

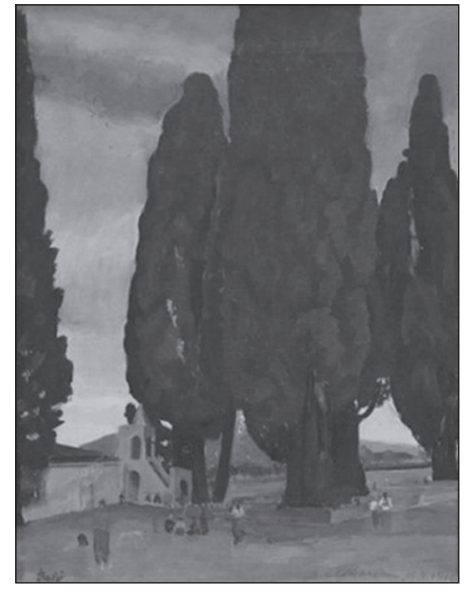

J. Batto, Parku kombëtar në Elbasan, tablo e vitit 1916

në këndvështrime të veçanta. Ndryshe nga Luwig Hesshaimer që dha madhështinë e tyre në një natë me yje, autori anglez jep efektet e lartësisë në një ditë me diell ku edhe hijet duken po aq befasuese. Të kësaj periudhe janë disa krijime të çekut Stanislav Nojman që qëndroi dhe pikturoi për një kohë të gjatë pranë tyre. Ndërsa nga një zbulim i fundit del se një nga pikturat më të bukura, e realizuar po në ato vite, i takon nga piktorit József Bató (18881966). Tabloja me titullin "Parku kombëtar në Elbasan" (National park in Elbassan, Albanien, 1916), është e pikturuar me ngjyra vaji në kanavacë (në përmasat 54 x $42 \mathrm{~cm}$ ). Selvitë e larta aty jepet me ngjyra të plota e pastoze, çka bën që pemët e larta të duken më madhështore. Eshtë realizuar nga i njëjti pikëvështrim me me tablonë e Hesshaimer-rit. Aty duket edhe një godinë e vogël kulti, e gjendur mes trungjeve të trashë të pemëve që ngrihen përmbi çati.

Selvitë e larta përmenden edhe nga çifti i artistëve anglezë Jan dhe Cora Gordon në librin e tyre me vizatime dhe shënime udhëtimi nëpër Shqipëri (Two Vagabonds in Albania, London 1927). Aty nuk kanë botuar ndonjë skicë për selvitë, ndërkohë që i përmendin për hijeshinë dhe madhështinë e tyre. Edhe nga piktori Edward Lear, deri vonë nuk njihej asnjë vizatim apo akuarel. Dukej e pabesueshme që prirjeve të tij romantike t’i kishte shpëtuar një pamje e tillë magjepse, aq më tepër kur mendon se ai kishte kaluar nëpër 


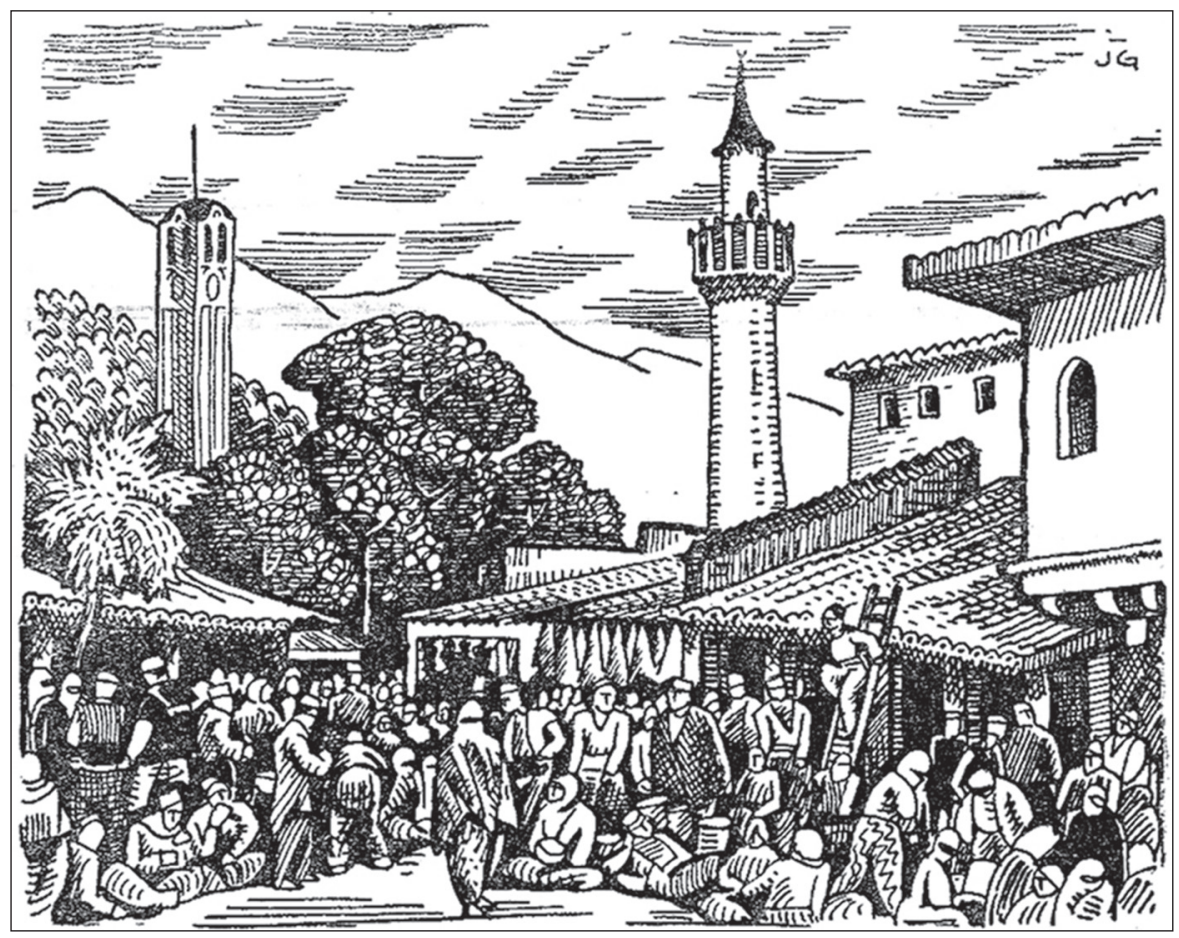

C. Gordon, Tregu në Elbasan, vizatim i vitit 1925

Elbasan shumë kohë përpara piktorëve të mësipërm. Lear udhëtoi në vitin 1848 , rreth gjashtëdhjetë vjet më përpara se L. Hesshaimer, pra në një kohë relativisht më të re për nga lulëzimi të selvive të Namazgjasë. Nga kërkimet në Hougton Library të Universitetit të Harvardit, ku ruhet pjesa më e madhe e krijimeve të Lear-it për Shqipërinë, mësojmë se ekziston një vizatim me sepia dhe akuarel. Sipas kartelës së muzeut, në shënimet e piktorit për nuancat e ngjyrave, poshtë vizatimit, mbisundon disa herë fjala "e errët" ( "dark" "very dark" "cypresses very blue" "women wear black", nga shënimet rreth tablosë). Siç duket Lear ka kaluar pranë tyre afër mbrëmjes dhe nuk ka mundur të bëjë më shumë se një skicim të shpejtë. Përndryshe do të kishte realizuar një tablo të frymëzuar, siç bëri për malin e Tomorit, për malet Akrokeraune apo për pamje të tjera magjepsëse nga natyra shqiptare që i vështroi në ditët me diell, në çastet kur ngjyrat dhe drita mesdhetare krijojnë atmosferë më frymëzuese për artistët.

Rreth njëzetepesë vjet më vonë, në pranverën e vitit 1939, midis grupit të artistëve italianë që erdhën për të pikturuar nëpër Shqipëri, edhe piktori Libero Augenti zgjodhi Selvitë e Elbasanit si motivin më tërheqës për krijimet e tij në pikturë. Pasi realizoi disa vizatime dhe etyde nga këndvështrime të 


\section{Albanon}

\section{Revistë kulturore}

ndryshme, në ekspozitën e Konkursit Premio Albania paraqiti peizazhet Selvitë e Namazgjah-ut dhe Pus i vjetër në Namazgjah. Nga kërkimet e deritanishme ende nuk njihen të gjitha imazhet e tablove, vizatimeve apo gravurave që janë realizuar nga autorët e huaj. Grumbullimi i tyre në këtë koleksion të përbashkët, do ta pasurojë më tej galerinë e veprave kushtuar atij monumenti të bukur natyror.

Deri në vitin 1990, me përjashtim të një peizazhi të Zef Kolombit (“Namazgjaja”, 1938), selvitë e pikturuara nga disa artistë të huaj që kishin kaluar nëpër Elbasan, nuk kishin gjetur vend në tablotë e autorëve vendas, të cilët jetonin dhe krijonin çdo ditë aty pranë tyre. Ndryshe nga malet Akrokeraune në bregdetin e Jugut, që për t’i vizatuar më bukur duhet t'i shohësh nga një distancë e largët, nga Korfuzi, andej nga u frymëzuan edhe artistët e huaj, selvitë e Elbasanit lëshonin hijet e gjata midis qytetit, aty ku kalonin çdo ditë banorët dhe artistët vendas. Ato qëndronin gjithë kohës midis njerëzve, ngriheshin shtatlarta si modele të bukura në një studio të hapur, sikur pozonin për t'u pikturuar apo fotografuar. Mungesa e tablove nga autorët shqiptarë deri para viteve ' 90 shpjegohet me trysninë e kohës, kur nuk ishte i preferuar pikturimi i mjediseve ku ishin zhvilluar ceremoni fetare, sado të bukura qofshin ato. Pikërisht në kohën kur selvitë ishin ende në lulëzim dhe mund të krijoheshin tablo të mrekullueshme me imazhin e tyre, artistët orientoheshin të rendnin drejt peizazheve të transformuara nga dora e njeriut të ri.

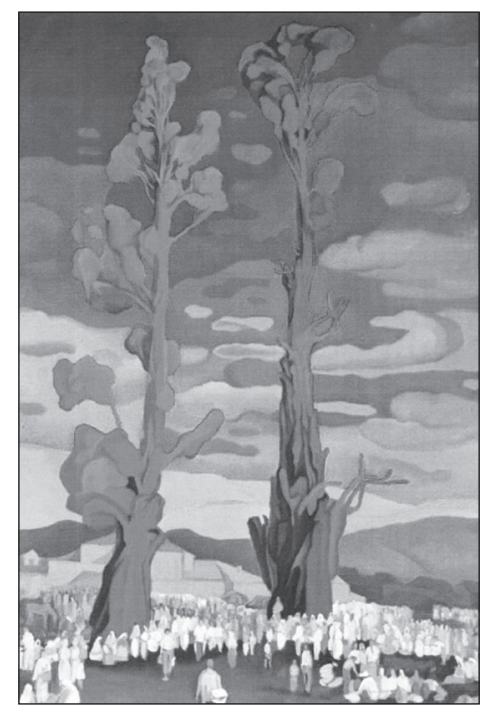

I. Sulovari, Selvitë, tablo e vitit 1990
Kështu kaluan vitet. Selvitë humbën madhështinë dhe bukurinë e dikurshme, artistëve $u$ iku duarsh mundësia për t'i pikturuar. Deri vonë mendohej se prej piktorëve elbasanas nuk ishte krijuar asnjë pikturë edhe pas viteve '90. Në asnjë ekspozitë nuk ishin paraqitur tablo me pamjen e tyre. Por në Galerinë e Artit Kasa gjendet një nga pikturat e bukura me këtë motiv e krijuar nga piktorit Isuf Sulovari (1935-2006). Peizazhi Selvitë e Namazgjasë, i ekspozuar në vitin 2010 në fondin e kësaj galerie, është realizuar rreth vitit 1990. Të pikturuara në një telajo me prerje vertikale (76 x $52 \mathrm{~cm}$.), selvitë, ndonëse shfaqen në kohën e degradimit të 
tyre, duken megjithatë madhështore. Në realizimin e asaj tabloje, mjeshtri Sulovari ka sjellë në ndihmë kujtesën e tij, nostalgjinë e shumë viteve më parë kur pemët ishin ende të drejta, të larta dhe të lulëzuara. Evidentimi i lartësisë në tablo, duke i pikturuar në përmasa shumë më të mëdha, në krahasim me figurat e njerëzve që lëvizin pranë trungjeve, të sjell ndër mend përfytyrimet jo reale të kohës së fëmijërisë, kur përmasat e objekteve duken më të mëdha se ç’janë realisht. Gjurmët e asaj moshe janë të dukshme në tablo. Gjatë "ringjalljes" së selvive të larta ndjehet dhimbja e piktorit për degradimin e tyre, si dhe pengu i pamundësisë për t'i pikturuar vite më parë. Kjo tablo paraqet një ndër rastet e rralla dhe më të veçanta në pikturën shqiptare kur, përmes pikturës, na paraqitet një imazh i bukur artistik, i ruajtur gjatë në kujtesën e artistit si motiv i ndaluar për t'u prekur në kohën e tij, por që do të pikturohej vite më pas.

\section{Bibliografi:}

Revista Vllaznia, 21 gusht, Vjenë, 4 shtator 1918;

Revista Djalëria, Vjenë, 1922;

Wallish, F.: Albanien und seine postwerizeichen, Wiene, 1927;

Çelebi, E.: Shqipnia para tre shekujsh (përkthyer nga S. Vuçiterni), Besa,Tiranë, 1930, f. 99;

Gordon J., Gordon, C.: Two Vagabonds in Albania, London, 1927;

Shënime nga bashkëbisedimi me Prof. Aleks Buda, dorëshkrim, Tiranë, 1985, arkivi personal

F.H; Shënime nga bisedat me Prof. Dhimitër Shuteriqi, dorëshkrim. Tiranë, dhjetor 1986, arkivi personal F.H; Hudhri, F.: Albania and Albanians in the World Art, Athens, 1990, f. 96, 193, 278, 282; Shënime nga bashkëbisedime me banorë të hershëm dhe artistë të qytetit, Elbasan, 2008, 2010, dorëshkrim, arkivi personal F.H. 